\title{
EFEKTIFITAS PERMAINAN “DHAKO” PADA PEMBELAJARAN BERHITUNG DALAM BAHASA INGGRIS (MATHEMATIC) BAGI SISWA KELAS 5 SDN AENGDAKE I
}

\author{
Akhmad Feri Fatoni ${ }^{1}$, Anang Hadi Cahyono ${ }^{2}$ \\ ${ }^{1}$ universitas Wiraraja \\ Email:akhmadferi@wiraraja.ac.id \\ ${ }^{2}$ Universitas Wiraraja \\ Email: ananghadicahyono@wiraraja.ac.id
}

\begin{abstract}
Abstrak
Salah satu materi pelajaran bahasa Inggris yang menjadi dasar untuk belajar pada level selanjutnya adalah berhitung dalam bahasa Inggris (mathematic). Disebabkan pelajaran bahasa Inggris sangat berbeda dengan bahasa Indonesia sebagai bahasa ibu, seorang guru harus menerapkan konsep belajar yang menarik. "Dhako" sebagai sebuah permainan berkearifan lokal merupakan sebuah variabel yang penting untuk dijadikan media pembelajaran agar siswa tidak kehilangan nilai-nilai kedaerahan. Penelitian ini bertujuan untuk mengetahui efisiensi permainan "dhako" pada pembelajaran berhitung dalam bahasa inggris (mathematic). Penelitian ini menggunakan quasy-eksperimen dengan pre-post test. Dari total dua puluh satu siswa dibagi dalam kelompok kontrol dan eksperimen dengan menggunakan metode random. Uji statistik menggunakan Paired T Test, Levene's Test, dan Independent T Test. Hasil pada uji Paired T Test Paired Sample Test diketahui terdapat perbedaan rata-rata antara hasil belajar pre test dan post nilai signifikansi (2-tailed) sebesar 0,002 $<0,05$. Levene's Test for Equality of Variances adalah sebesar 0,882 > 0,05 yang berarti kelas Intervensi dan kelas Kontrol adalah sama atau homogen. Independent Samples Test sebesar 0,039 $<0,05$ menyimpulkan bahwa ada perbedaan efektifitas yang signifikan (nyata) antara penggunaan permainan dhako pada pembelajaran berhitung dalam bahasa inggris (mathematic) dan tidak menggunakan permainan dhako pada pembelajaran berhitung dalam bahasa inggris (mathematic) bagi siswa kelas 5 SDN AENGDAKE I.
\end{abstract}

Kata kunci: Permainan Dhako, Mathematic, Siswa kelas V

\begin{abstract}
One of the English subject matter that becomes the basis for learning at the next level is counting in English (mathematics). Teacher must apply interesting learning concepts due to English is very different from Indonesian as a mother tongue. "Dhako" as a game of local wisdom is an important variable to be used as a learning medium so that students do not lose regional values. This study aims to determine the efficiency of the game "dhako" in learning to count in English (mathematical). This study used a quasi-experiment with pre-post test. From a total of twenty one students were divided into control and experimental groups using random methods. Statistical test using Paired T Test, Levene's Test, and Independent T Test. The results of the Paired T Test Paired Sample Test, it is known that there was an average difference between pre-test and post-test learning outcomes with a significance value (2-tailed) of $0.002<0.05$. Levene's Test for Equality of Variances was $0.882>0.05$, which means that the Intervention and Control classes were the same or homogeneous. The Independent Samples Test of $0.039<0.05$ concluded that there was a significant (significant) difference in effectiveness between the use of "dhako" games in learning to count in English (mathematic) and conventional in learning to count in English (mathematic) for grade 5 students. SDN AENGDAKE I.
\end{abstract}

Keywords: "Dhako game, mathematic, students class $V$ 


\section{PENDAHULUAN}

Proses belajar mengajar merupakan kegiatan transformasi ilmu antara pelajar (siswa) dan guru sebagai pengajar, yang dalam pelaksanaannya berlangsung interaksi antara guru dengan peserta didik dalam sebuah situasi edukasi. Indikator keberhasilan proses belajar mengajar ditentukan oleh kerjasama antara guru pengajar dengan peserta didik. Keberhasilan belajar ditandai oleh beberapa indikator, diantaranya; a). Daya serap siswa terhadap materi yang diajarkan; b). Capaian perilaku siswa merujuk pada RPP; dan c). Keterlanjutan materi secara sekuensi.

Pembelajaran seyogyanya dimulai dari dasar tingkat pendidikan, terlebih mata pelajaran bahasa Inggris yang memiliki tingkat kesulitan kompleks untuk dipelajari. Cara pelafalan, kosa kata, dan cara penulisan adalah tiga kesulitan utama dalam belajar bahasa Inggris, utamanya bagi siswa SD. Seorang siswa cenderung mengalami kesulitan apabila pemahaman dasar bahasa inggris kurang baik, sebaliknya siswa akan mudah memahami bahasa Inggris apabila paham dasar teorinya. Aedi dan Amaliyah (2017) mengatakan bahwa menghadapi zaman globalisasi yang serba instant ini, seorang anak pada level sekolah dasar telah dituntut untuk bersaing dalam sebuah mata pelajaran global, yaitu bahasa Inggris.

Bahasa Inggris yang digunakan sebagai alat komunikasi di berbagai belahan dunia barang tentu membawa serta ciri budaya dan keunikan setiap bangsa yang menggunakannya. Dialek, pelafalan, dan tingkah laku menjadi pembeda setiap kultur dalam penggunaan bahasa Inggris. Merujuk pada peraturan Pendidikan Nasional (Diknas 2003), kompetensi mata pelajaran bahasa Inggris adalah kecakapan komunikasi lisan maupun tulis siswa menggunakan raga, bahasa yang sesuai, lancar, dan akurat.

Dalam hal belajar berhitung dalam bahasa Inggris, agar lebih menarik dan efisien seorang guru harus menerapkan konsep belajar yang menarik. Disebabkan pelajaran bahasa Inggris sangat berbeda dengan bahasa Indonesia sebagai bahasa ibu. Namun pengajaran bahasa Inggris oleh guru mata pelajaran umum seringkali menggunakan metode konfensional. Sehingga minat siswa untuk belajar berhitung dalam bahasa Inggris kurang dan pada akhirnya berdampak pada tingkat pemahaman siswa. Maka dibutuhkan suatu media untuk meningkatkan minat belajar siswa pada level sekolah dasar. 
Penelitian ini menjadi penting untuk dilaksanakan karena berhitung dalam bahasa Inggris (mathematic) adalah materi dasar yang akan selalu digunakan dalam belajar bahasa Inggris di segala level. Penjumlahan, pengurangan, pembagian, dan perkalian adalah beberapa sub topik yang harus dikuasi pada level pendidikan dasar. Di sisi lain, variabel yang bersifat kearifan lokal penting untuk diangkat sebagai media pembelajaran agar pada diri siswa tertanam nilai-nilai kedaerahan. Menurut I Wayan (2007), terdapat lima komponen dalam proses belajar mengajar yaitu guru, materi, media, siswa, dan tujuan pembelajaran. Artinya komunikasi dalam proses belajar mengajar tidak akan berjalan optimal tanpa penggunaan media didalamnya.

"Dhako", sebuah permainan tradisional yang masih sering dimainkan anak level sekolah dasar dalam aktivitas sehari-hari dapat dijadikan alternatif pembelajaran, khususnya dalam materi berhitung. Menurut Kemp dan Dayton (dalam Arsyad 2002) proses pembelajaran menjadi lebih menarik dengan menggunakan media permainan. Siswa dapat berinteraksi dengan apa yang dimainakan, baik dengan audio, video, maupun gerak. Dalam pembelajaran menggunakan permainan "dhako", siswa diarahkan untuk menghitung biji yang disebar dalam setiap lubang "dhako".

Namun rumusan masalah yang perlu dibuktikan adalah apakah dhako sebagai permainan tradisional efektif dalam meningkatkan keterampilan berhitung matematika bahasa Inggris siswa kelas 5 SDN Aengdake I?

Dikaitkan dengan mata pelajaran bahasa Inggris, siswa diharuskan untuk menghitug (mathematic) dalam bahasa Inggris, termasuk pelafalan penjumlahan, pengurangan, pengurangan, dan pembagian. Permainan "dhako" dinilai memiliki relefansi erat dengan materi berhitung dalam bahasa Inggris (mathematic) karena dalam permainan "dhako" siswa diharuskan untuk memiliki kepiawaian dalam berhitung. Sehingga permainan "dhako" diasumsikan dapat menjadi media untuk meningkatkan kemampuan berhitung dalam bahasa Inggris (mathematic).

Subjek penelitian ini dalah siswa kelas 5 SDN Aengdake I. SDN Aengdake I dipilih sebagai subjek penelitian ini karena pola pengajaran di sekolah tersebut spesifik pada mata pelajaran bahasa Inggris monoton, sehingga kemampuan bahasa Inggris siswa menjadi terbatas. Disamping itu, permainan dhako masih sering 
dimainkan oleh anak usia sekolah dasar di daerah desa aengdake.

Aengdake adalah sebuah desa di kecamatan Bluto yang terletak pada kawasan pesisir selatan Madura. Bila dikaitkan dengan roadmap penelitian Universitas Wiraraja, didapatkan sebuah kesesuaian antara penelitian ini dengan roadmap universitas, yakni subjek penelitian berfokus pada daerah pesisir.

Penelitian ini bertujuan untuk mengetahui signifikasi "dhako" sebagai permainan berkearifan lokal dalam meningkatkan keterampilan berhitung bahasa Inggris (mathematic) siswa. Sedangkan target penelitian ini adalah didapatkannya sebuah media berkearifan lokal dalam pembelajaran berhitung bahasa Inggris (mathematic) siswa SD kelas 5 .

\section{METODE PENELITIAN}

Penelitian ini bermula pada proses pembelajaran yang dilaksanakan di kelas pada level sekolah dasar, utamanya kelas 5 SDN Aengdake I spesifik mata pelajaran bahasa Inggris.

Metode penelitian yang digunakan dalam penelitian ini adalah quantitative analisis ( quasy-eksperiment). Menurut Creswell 2008, pada metode penelitian kuantitatif tidak ada pemilihan populasi, artinya penentuan sample pada penelitian ini adalah radom. Selain itu, menurut Azam,
Sumarno \& Rahmat (2006) mengatakan bahwa metode penelitian yang direkomendasikan untuk mengukur kualitas pembelajaran adalah teknik quasy-eksperiment

Desain penelitian pada penelitian ini memiliki beberapa kriteria, yaitu (a). Terdapat kelompok kontrol dan intervensi; (b). Kedua kelompok siswa diukur dengan indikator variabel bebas; (c). Masing-masing group mendapatkan pre dan post test. Aspek yang diukur dalam penelitian ini adalah kecakapan siswa dalam berhitung, meliputi menjumlah, mengurangi, mengalikan, dan membagi dalam bahasa inggris.

Sebelum dilaksanakan penelitian, peneliti menanyakan beberapa pertanyaan kepada guru pengajar bahasa Inggris terkait metode yang sering digunakan dalam pembelajaran. Selain pertanyaan kepada guru, peneliti juga menanyakan beberapa hal terkait kepiawaian siswa dalam berhitung dalam bahasa Inggris. Setelah didapat data mengenai studi awal penelitian, peneliti akan memberikan sebuah pre-test bagi siswa. Materi pada pre-test ini adalah seputar operasi berhitung sederhana dalam bahasa Inggris. Pemberian pertanyaan berupa oral question.

Setelah pemberian pre-test, peneliti memilah siswa kedalam dua grup, yaitu kontrol dan intrvensi 
menggunakan metode random sampling. Setelah grouping, peneliti akan memberikan materi dengan komposisi tiga kali tatap muka bagi masing-masing grup. Dan pada akhir pertemuan peneliti akan memberikan post-test bagi seluruh siswa.

\section{HASIL DAN PEMBAHASAN}

Pada pelaksanaan penelitian ini, peneliti melakukan beberapa kegiatan, yaitu:

a. pemberian angket

Sebelum melakukan kegiatan inti oenelitian, peneliti terlebih dahulu melakukan beberapa kegiatan, yaitu pemberian angket terkait pelaksanaan pembelajaran bahasa Inggris yang dilaksanakan di sekolah. Hasil pemberian angket dapat dilihat pada tabel dibawah ini

b. pelaksanaan kegiatan penelitian instrumen penilaian pada penelitian ini adalah tes oral seputar pengetahuan siswa tentang penggunaan bahasa Inggris siswa dalam operasi berhitung (mathematic). Terdapat dua kali test yang dilaksanakan, yaitu pre-test dan post-test. Hasil pretest dan post-test dapat dilihat pada tabel dibawah ini.

\section{Hasil perhitungan uji n-gain score}

\begin{tabular}{|c|c|c|c|}
\hline \multirow{2}{*}{ No } & $\begin{array}{c}\text { Kelas } \\
\text { Intervensi }\end{array}$ & No & $\begin{array}{c}\text { Kelas } \\
\text { Kontrol }\end{array}$ \\
\cline { 2 - 4 } $\begin{array}{c}\text { N-Gain Score } \\
(\%)\end{array}$ & $\begin{array}{c}\text { N-Gain } \\
\text { Score (\%) }\end{array}$ \\
\hline 1 & 25.81 & 1 & 57.14 \\
\hline 2 & 41.18 & 2 & 61.29 \\
\hline 3 & 10.71 & 3 & 70.97 \\
\hline 4 & 17.65 & 4 & 64.71 \\
\hline 5 & .00 & 5 & 82.35 \\
\hline 6 & 25.81 & 6 & 57.14 \\
\hline 7 & 41.18 & 7 & 70.97 \\
\hline 8 & 19.35 & 8 & 57.14 \\
\hline 9 & 28.57 & 9 & 61.29 \\
\hline 10 & 19.35 & 10 & 78.57 \\
\hline & & 11 & 88.00 \\
\hline $\begin{array}{l}\text { Rata- } \\
\text { Rata }\end{array}$ & 22.9608 & Rata-Rata & 68.1432 \\
\hline
\end{tabular}

\begin{tabular}{|l|c|l|l|}
\hline Minimal & .00 & Minimal & 57.14 \\
\hline Maksimal & 41.18 & Maksimal & 88.00 \\
\hline
\end{tabular}

$$
\text { Berdasarkan hasil perhitungan uji }
$$

$\mathrm{N}$-gain score diatas, menunjukkan bahwa nilai rata-rata $\mathrm{N}$-gain score untuk kelas Intervensi adalah sebesar 22,9608 atau $23 \%$ termasuk dalam kategori tidak efektif dengan nilai $\mathrm{N}$-gain minimal ,00 dan maksimal $41,18 \%$. Sementara untuk rata-rata $\mathrm{N}$-gain score kelas kontrol adalah sebesar $68,1 \%$ termsuk dalam kategori cukup efektif dengan nilai $\mathrm{N}$ Gain score minimal $57,14 \%$ dan maksimal $88,00 \%$.

Dengan demikian, maka dapat disimpulkan bahwa penggunaan permainan dhako pada pembelajaran berhitung dalam bahasa inggris (mathematic) cukup efektif diterapkan bagi siswa kelas 5 SDN AENGDAKE I.

\section{Kategori penilaian $\mathbf{n}$-gain score}

Kategorisasi penilaian N-Gain Score dapat ditentukan berdasarkan nilai $\mathrm{N}$-Gain maupun dari nilai $\mathrm{N}$-Gain dalam bentuk persen (\%). Adapun pembagian nilai $\mathrm{N}$-Gain dapat kita lihat pada tabel berikut :

\section{Pembagian Skor Gain}

\begin{tabular}{|c|c|}
\hline Nilai N-Gain & Kategori \\
\hline $\mathrm{g}>0,7$ & Tinggi \\
\hline $0,3 \leq \mathrm{g} \leq 0,7$ & Sedang \\
\hline $\mathrm{g}<0,3$ & Rendah \\
\hline
\end{tabular}

Sumber: Melzer dalam Syahfitri, 2008:33

Sementara, pembagian kategori perolehan pada N-Gain dalam bentuk

163 | Efektivitas Permainan "Dhako" pada Pembelajaran Berhitung dalam 
persen (\%) dapat mengacu pada tabel dibawah ini :

Kategori Tafsiran Efektivitas N-Gain

\begin{tabular}{c|c}
\hline Presentase (\%) & Tafsiran \\
\hline$<40$ & Tidak Efektif \\
\hline $40-55$ & Kurang Efektif \\
\hline $56-75$ & Cukup Efektif \\
\hline$>76$ & Efektif \\
\hline \multicolumn{2}{c}{ Sumber: Hake,R.R, 1999}
\end{tabular}

\section{Uji Paired Sample T-Test}

\section{A. Kelas intervensi}
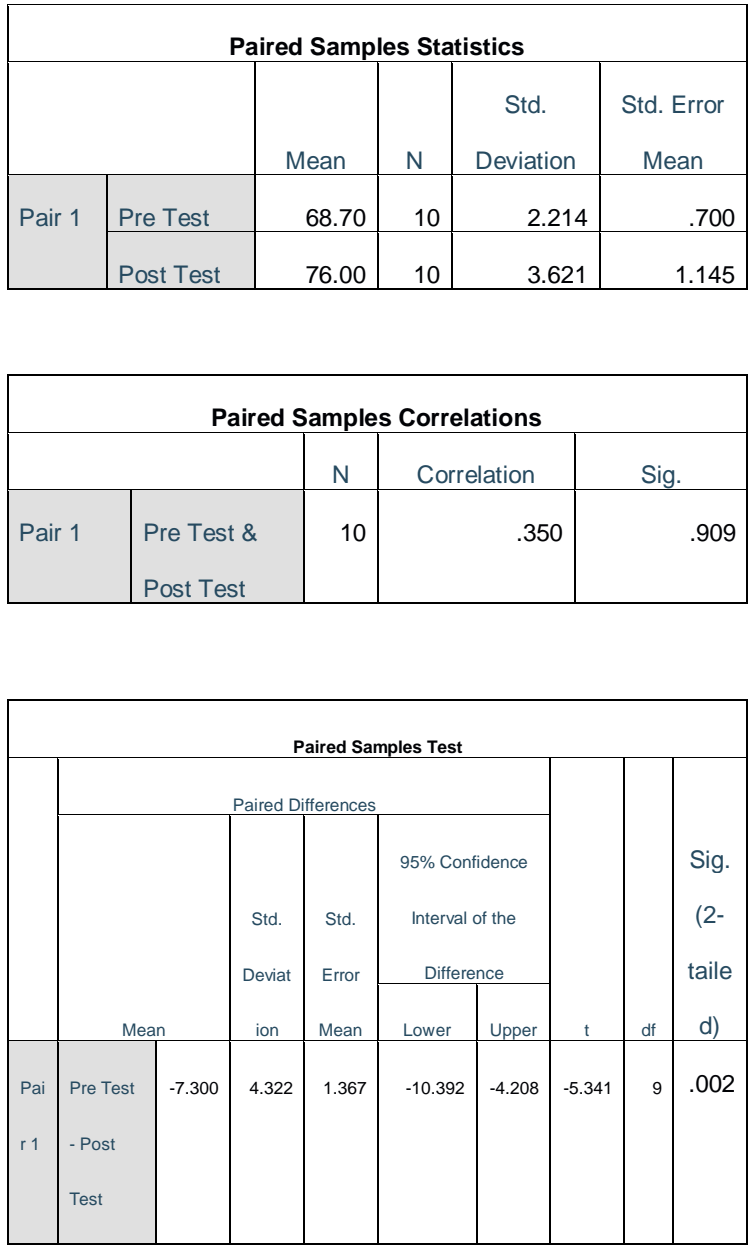

Berdasarkan tabel Paired Sample Statistics diatas rata-rata hasil belajar pada pre test $68,70<$ post test 76,00 maka artinya secara deskriptif terdapat perbedaan rata-rata hasil belajar antara pre test dan post test dikelas Intervensi. Sedangkan uji hasil korelasi atau hubungan kedua data atau hubungan variabel pre test dan post test diketahui nilai koefisien korelasi (Correlation) 0,350 dengan nilai signifikansi (sig) sebesar $0,909>0,05$ maka dapat dikatakan bahwa tidak ada hubungan antara variabel pre test dan post test dikelas Intervensi.

Selanjutnya pada tabel Paired Sample Test diketahui nilai signifikansi (2-tailed) sebesar 0,002 < 0,05 maka $\mathrm{Ha}$ di terima dan Ho di tolak. Sehingga dapat disimpulkan bahwa ada perbedaan rata-rata antara hasil belajar pre test dan post test dikelas Intervensi.

\section{B. Kelas kontrol}

\begin{tabular}{|c|c|c|c|c|c|}
\hline \multicolumn{6}{|c|}{ Paired Samples Statistics } \\
\hline & & Mean & $\mathrm{N}$ & $\begin{array}{c}\text { Std. } \\
\text { Deviatio } \\
\mathrm{n}\end{array}$ & $\begin{array}{l}\text { Std. } \\
\text { Error } \\
\text { Mean }\end{array}$ \\
\hline \multirow{2}{*}{$\begin{array}{l}\text { Pair } \\
1\end{array}$} & Pre Test & 70.09 & 11 & 2.773 & .836 \\
\hline & $\begin{array}{l}\text { Post } \\
\text { Test }\end{array}$ & 90.45 & 11 & 3.236 & .976 \\
\hline
\end{tabular}

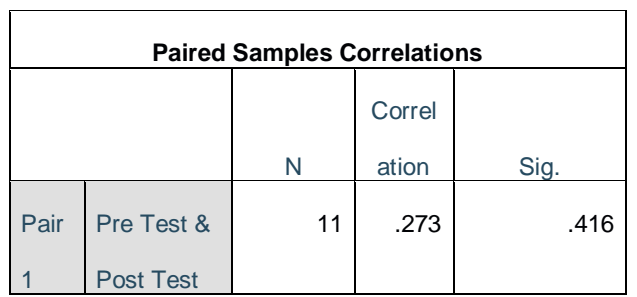




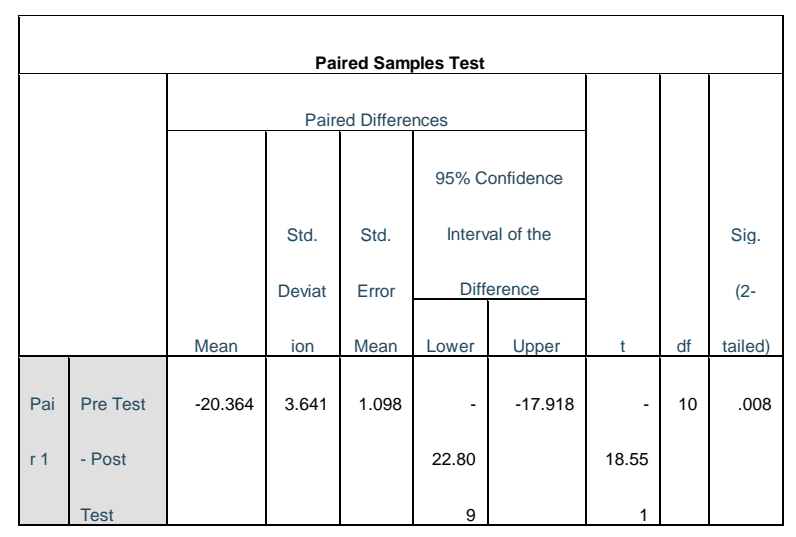

Berdasarkan tabel Paired Sample Statistics diatas rata-rata hasil belajar pada pre test $70,09<$ post test 90,45 maka artinya secara deskriptif terdapat perbedaan rata-rata hasil belajar antara pre test dan post test dikelas Kontrol.

Sedangkan uji hasil korelasi atau hubungan kedua data atau hubungan variabel pre test dan post test diketahui nilai koefisien korelasi (Correlation) 0,273 dengan nilai signifikansi (sig) sebesar $0,416>0,05$ maka dapat dikatakan bahwa tidak ada hubungan antara variabel pre test dan post test dikelas Kontrol. Selanjutnya pada tabel Paired Sample Test diketahui nilai signifikansi (2-tailed) sebesar 0,008< 0,05 maka Ha di terima dan Ho di tolak.

Sehingga dapat disimpulkan bahwa ada perbedaan rata-rata antara hasil belajar pre test dan post test dikelas Kontrol.

\section{Uji Independent Sample T-Test}

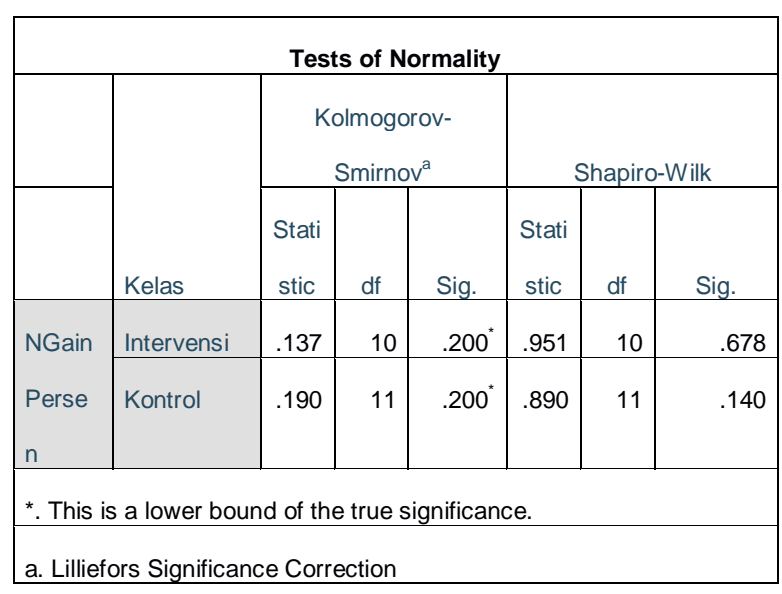

Berdasarkan tabel Test of Normality diatas, diketahui nilai signifikasi (Sig) untuk kelas Intervensi sebesar 0,678 dan kelas Kontrol sebesar 0,140 . Karena nilai signifikansi kedua kelas tersebut lebih besar dari 0,05 maka dapat dikatakan bahwa data yang digunakan dalam penelitian ini adalah berdistribusi normal. Dengan demikian persyaratan penggunaan uji independent sample T-test untuk $\mathrm{N}$-gain score sudah terpenuhi.

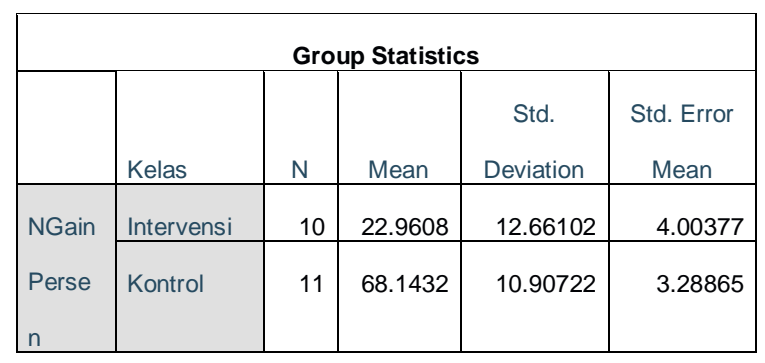




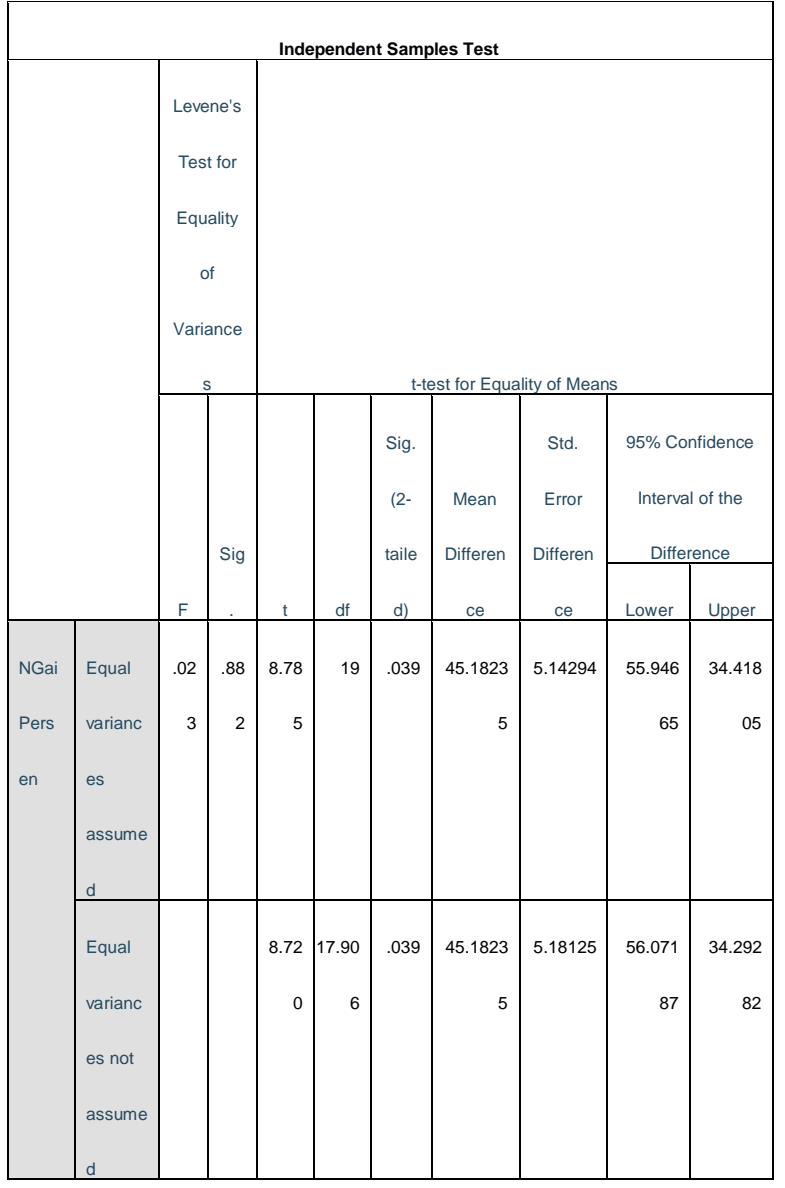

Berdasarkan tabel output diatas diketahui nilai signifikansi (sig) pada Levene's Test for Equality of Variances adalah sebesar 0,882 >0,05 maka dapat disimpulkan bahwa varians data $\mathrm{N}$-gain
(\%) untuk kelas Intervensi dan kelas Kontrol adalah sama atau homogen. Dengan demikian maka uji independent sample T-test untuk $\mathrm{N}$-gain score berpedoman pada nilai signifikansi yang terdapat pada tabel Equal variances assumed.

\section{KESIMPULAN}

Berdasarkan tabel output "Independent Samples Test" diatas diketahui nilai signifikansi (2-tailed) adalah sebesar 0,039<0,05 dengan demikian dapat disimpulkan bahwa ada perbedaan efektifitas yang signifikan (nyata) antara penggunaan permainan dhako pada pembelajaran berhitung dalam bahasa inggris (mathematic) dan tidak menggunakan permainan dhako pada pembelajaran berhitung dalam bahasa inggris (mathematic) bagi siswa kelas 5 SDN AENGDAKE I.

\section{DAFTAR PUSTAKA}

Aedi, N \& Amaliyah, N. (2017). Manajemen Kurikulum Sekolah. Gosyen Publishing. Yogyakarta

Azam, Prof. Nurfani SU, Apt, DR. Sumarno \& DR Adi Rahmat, 2006, Metodologi Penelitian Untuk Peningkatan Kualitas Pembelajaran Penelitian Kuasi Eksperimen dalam PPKP, Direktorat Ketenagaan Direktorat Jendral Pendidikan Tinggi Departemen Pendidikan Nasional

Creswell, J. W. (2008). Research Design: Qualitative, quantitative, and mixed method approaches. SAGE Publications, Incorporated

Kemp dan Dayton. (1985:28). dalam kutipan Arsyad (2002) Media Pembelajaran. Jakarta: PT Raja Garfindo Perasada 
Kompas. (2018). Bupati Sumenep Tekankan Permainan Berbasis Kearifan Lokal Harus Di Laksanakan. Diakses pada 28 Februari 2021 melalui http://kompasmadura.com/2018/12/13/bupati-sumenep-tekankan-permainanberbasis-kearifan-lokal-harus-di-laksanakan/

Rusmana, Dheka D.A. 2010. Permainan Congkak; Nilai dan Potensinya Bagi Perkembangan Kognitif Anak. Balai Pelestarian Sejarah dan Nilai Tradisional Bandung

Santyasa, I Wayan. 2007. Landasan Konsepsual Media Pembelajaran. Makalah Disajikan dalam Workshop Media Pembelajaran bagi Guru-Guru SMA Negeri Banjar Angkan Pada tanggal 10 Januari 2007 di Banjar Angkan Klungkung.

Undang-Undang No. 20 tahun 2003 Tentang Sistem Pendidikan Nasional. Jakarta 